\title{
Variability of sediment processes around a tidal farm in a theoretical channel
}

\author{
Christelle Auguste ${ }^{a}$, Jean-Roch Nader ${ }^{a}$, Philip Marsh ${ }^{a}$, Remo Cossu ${ }^{b}$, Irene Penesis ${ }^{a}$ \\ ${ }^{a}$ Australian Maritime College, University of Tasmania, Launceston TAS 7250, Australia \\ ${ }^{b}$ School of Civil Engineering, University of Queensland, St Lucia QLD 4072, Australia
}

Sediment transport plays a crucial role in coastal ecosystems and is one of the least known parameters in high energy sites. The recent development of tidal energy projects challenges the scientific community to better understand this natural phenomenon and the interactions with tidal turbines. Using MIKE21/3 software from DHI, a benchmark for sediment transport model was developed with simulations with and without a tidal farm in idealised two and three-dimensional tidal channels. Results reveal that a 2D approach is sufficient for regional scale morphological assessments, however 3D models allow for a closer examination of influences around the tidal farm. Differences in calculating sediment transport rates based on approaches after Engelund \& Fredsøe and Van Rijn formulae illustrate the degree of uncertainty in modelling sediment transport rates. Results for the Engelund \& Fredsøe models also show that they are sensitive to mesh resolution in equilibrium conditions and are more stable in non-equilibrium conditions for the bed level change rates. Tests have also demonstrated that models using Engelund \& Fredsøe formulae are more sensitive to physical characteristics than models based on Van Rijn, accentuating the necessity to evaluate sediment transport formulae with field data before making a choice of model.

Keywords: Tidal Energy, Sediment Transport, Tidal Energy Converters

\section{Introduction}

Erosion and accretion of sediments shape the morphology of the seabed, changing the distribution of nutrients and affecting the ecosystem. The influence of tidal energy converters on seabed characteristics is a growing object of concern for tidal energy developers as the industry emerges. The significance of sediment transport is widely recognized as a crucial component for tidal site assessment [1, 2. Previous studies have shown that small arrays of less than $50 \mathrm{MW}$ have an insignificant influence on the marine environment in a narrow tidal channel [3, 4, 5]. However, sediment studies at high flow sites are rare, as acquiring data is expensive and challenging in these highly energetic sites. To remove uncertainties about the influence of a tidal farm on sediment transport processes, or the influence on the turbines themselves, the interaction needs to be better understood. Numerical modelling is a useful tool for preliminary studies to assess the possible influence. Factors such as currents, waves, bathymetry and seabed composition must be considered for the accurate 
prediction of sediment transport. Unlike hydrodynamic modelling, little to no case studies exist for sediment modelling. The physical mechanism of the coastal environment is difficult to simulate due to many parameters influencing the motion of sediments [6]. The majority of coastal sediment transport models have adopted the equilibrium transport concept [7], but recently non-equilibrium approaches have received increasing attention [8] for a more realistic approach as they take into account the temporal and spatial lag between current and sediment transport rates, and capture morphological change accurately compared with previous models.

The most commonly used methods to predict total load sediment transport rates were developed by Engelund \& Hansen [9], Engelund \& Fredsøe [10], Ackers \& White [11], and Van Rijn [12, 13]. In these formulae total load transport is composed of bed load transport (mobile load close to the bed in almost continuous contact with the seafloor) and suspended load transport (load that is no longer in contact with the seafloor due to turbulent flow higher in the water column). These two components drive the behavior of morphodynamics. Numerous studies have compared well known sediment transport formulae [14, 15, 16, 17, 18, 19]. Significant differences were found in [15, 16] between the formulae, with factors of 2 for pure current to 5 for wave current dominated flows. The main source of uncertainty for [17] is the choice of the transport formulae in contradiction with [19] who affirmed that the errors in sediment rates depend on errors in physical properties like current velocity. A dependence on medium grain size exists as well for the calculation of transport rates. The results illustrate the degree of uncertainty in calculating sediment transport rates. If in situ data or experimental data is available, an evaluation of the most accurate formulae can be made. But when this information is unavailable as in most cases, error of up to a factor of 5 for sediment transport rates can occur [20]. In MIKE21/3 the most commonly approach used in coastal systems is Van Rijn (VR) for pure current, and Engelund \& Fredsøe (EF) in the wave current interactions. The VR formulae have been validated against experimental data and field data and compared to different formulae [12, 13, 21]. Two studies have evaluated the difference between the two formulae: comparing results between eleven sediment transport formulae [22] and in some test cases using approaches described in the software manual COHERENS [23]. Nakato [22] found that EF produced the lowest sediment transport rates for most of the tests. Using the software COHERENS, results showed that for medium to coarse sand under low shear stress the formulae were in the same range for transport rates.

The work outlined in this paper focused on developing a benchmark for sediment transport models. This benchmark study uses the numerical model MIKE21 Flexible Mesh (FM) and MIKE $3 \mathrm{FM}$ to examine the sensitivity of the developed sediment model in idealised tidal channels with pure current, with and without a simulated tidal farm. To examine the influence of a tidal farm on hydrodynamic and sediment dynamics, a farm of 500 turbines was simulated for some test cases. Studies of sediment transport processes around the tidal farm were performed for the near field area around the turbines and also for the far field effects in 2D and 3D. The sediment transport VR and EF formulae were compared in equilibrium and non-equilibrium modes for both 2D and 3D simulations. This study will serve as a benchmark for sediment transport studies allowing a better understanding of this complex phenomenon in a more elementary system than realistic cases, necessary step before apply- 
ing the model in real environment. This study is also part of a larger work to examine the influence of a tidal farm in Banks Strait, Tasmania, a promising tidal energy site identified by the "Tidal Energy in Australia-Assessing Resource and Feasibility to Australia's Future Energy Mix" Project (AUSTEn project [24]).

\section{Modelling Methodology}

The numerical modelling approach, the validation of the tidal energy extraction model and the model set up used for this study are highlighted below.

\subsection{General Description}

For all simulations, the MIKE21 FM and MIKE3 FM hydrodynamic models were used, which are based on the cell-centred finite volume method. These models use an unstructured mesh to allow for changes in resolution within the domain depending on the area of interest, reducing computational time. Reynolds-averaged Navier-Stokes (RANS) equations are solved in the model, with the Boussinesq assumption and hydrostatic pressure [25]. To model sediment transport, the module quasi 3Dimensional "Sand Transport" is used, which determines the transport of non-cohesive particle (common feature in these high energy sites) based on both the hydrodynamic conditions and sediment properties [26]. Sediment motion occurs when the value of the dimensionless bed shear stress (Shields parameter) exceeds a set threshold value (the critical Shields parameter). Two formulae for sediment transport rates were examined: Engelund \& Fredsøe [10] and Van Rijn [12, 13, in equilibrium and nonequilibrium conditions. In the equilibrium condition sediments react instantaneously with the flow, whereas in the non-equilibrium condition phase lag effects are included (time to adapt the concentration profile over the water column). For the change in bed bathymetry the Exner sediment continuity equation is solved at each timestep using:

$$
-(1-n) \frac{\partial z}{\partial t}=\frac{\partial S_{x}}{\partial x}+\frac{\partial S_{y}}{\partial y}-\Delta S
$$

where $n$ is the bed porosity, $z$ is the bed level, $t$ is the time, $S_{x}$ is the total load in the x direction, $S_{y}$ is the total load in the y direction and $\Delta S$ is the sediment sink or source rate. For equilibrium conditions, the source term is zero, except if lateral sediment supply is included in the model. If the advection-dispersion equation is considered (non-equilibrium condition) the source term is defined by:

$$
\Delta S=\Phi_{0}\left(\eta_{0}\right) w_{s}\left(c-c_{e}\right)
$$

where $\Phi_{0}$ is the unit profile function for the sediment concentration, $\eta_{0}$ is the normalised no slip level above the bed, $w_{s}$ is the settling velocity for suspended sediment, $c$ is the depth averaged sediment concentration and $c_{e}$ is the depth averaged equilibrium concentration.

Two idealised theoretical channel-bay systems of different length were created, with dimensions outlined in Table 1. They are based on a commonly studied benchmark test case [5] adapted from [27] which is often used for validation of the energy extraction models. The 
tidal channel is connected to a tidal bay and an open ocean (Fig,1). On the open ocean boundary, one meter of tidal amplitude is applied. The model is considered barotropic to reduce computational time.

Table 1: Geometry of the domains used for the simulations

\begin{tabular}{lccc}
\hline Domain & Length $(\mathrm{km})$ & Width $(\mathrm{km})$ & Depth $(\mathrm{m})$ \\
\hline Open Ocean & 200 & 240 & 200 \\
Tidal Channel & $30 / 60$ & 6 & 60 \\
Tidal Bay & 150 & 30 & 100 \\
\hline
\end{tabular}

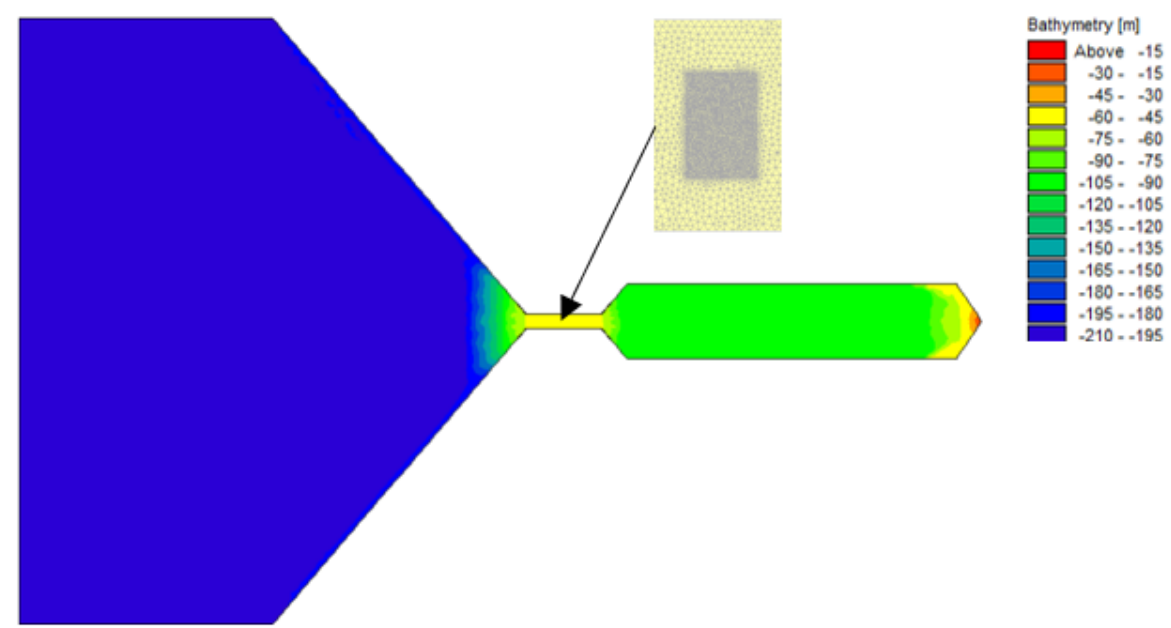

Figure 1: Bathymetry in the domain and zoom of the mesh for tidal farm cases in the tidal channel

Tidal turbines are represented in MIKE21/3 as a sub-grid object with their influence on the hydrodynamics based on actuator disc theory. The turbines are modelled as a momentum sink terms which are related to the thrust exerted by the turbine, method commonly applied for the study of tidal farm energy extraction [28, 29, 30, 31, 32, 33. For each mesh layer the influence of turbines is modelled by calculating the current induced drag and lift force on each layer [25]. The effective drag force, $F_{D}$ and $F_{L}$ are defined as:

$$
\begin{aligned}
F_{D} & =\frac{1}{2} \rho \alpha C_{D} A_{e} U_{0}^{2} \\
F_{L} & =\frac{1}{2} \rho \alpha C_{L} A_{e} U_{0}^{2}
\end{aligned}
$$

where $\rho$ is the density of water (equal to $1025 \mathrm{~kg} / \mathrm{m} 3$ ), $\alpha$ a correction factor (set to 1 in this study), $C_{D}$ is the drag coefficient, $C_{L}$ is the lift coefficient, $A_{e}$ is the effective area of 
turbine exposed to current and $U_{0}$ is the upstream current speed. Although this method could lead to inaccuracies in the near field wake and did not account for detailed design, it is appropriate for assessing environmental influence on the marine environment [34]. For the near field, results should be interpreted with caution.

\subsection{Validation of the tidal energy extraction model}

The short tidal channel for tidal energy extraction modelling was validated by comparing the 2D MIKE model against results from literature using a 2D Marine and HydroKinetic software module in Finite Volume Coastal Ocean Model (FVCOM) [27, 5]. The power generated by the turbines is calculated using:

$$
P=\frac{1}{2} \rho C_{T} A_{b} \bar{U}^{3}
$$

where $A_{b}$ is the turbine cross-sectional area and $\bar{U}^{3}$ is the average of tidal current speed over a tidal cycle. In this study the turbines face the flow at all time and thus $C_{D}=\mathrm{C}_{T}$ (thrust coefficient) and $C_{L}=0$. The turbines parameters were based on the dimensions from the 2D (FVCOM) model: $C_{T}$ was set to 0.5 , the diameter of the turbine was set to $10 \mathrm{~m}$ given $A_{b}$ equal to $78.54 \mathrm{~m} 2$, and the hub height was set to $10 \mathrm{~m}$.

A baseline condition was simulated with no turbine. Five additional cases were then performed corresponding to: one, two, five, six and nine turbines in each cell of the tidal channel (comprised of a total of 10855 cells in the channel). The simulated extractable power was then compared with the Yang studies results [27] (data were given in personal communication, 26/01/19) (Fig,2). Model results were very close to the results of the (FVCOM) model

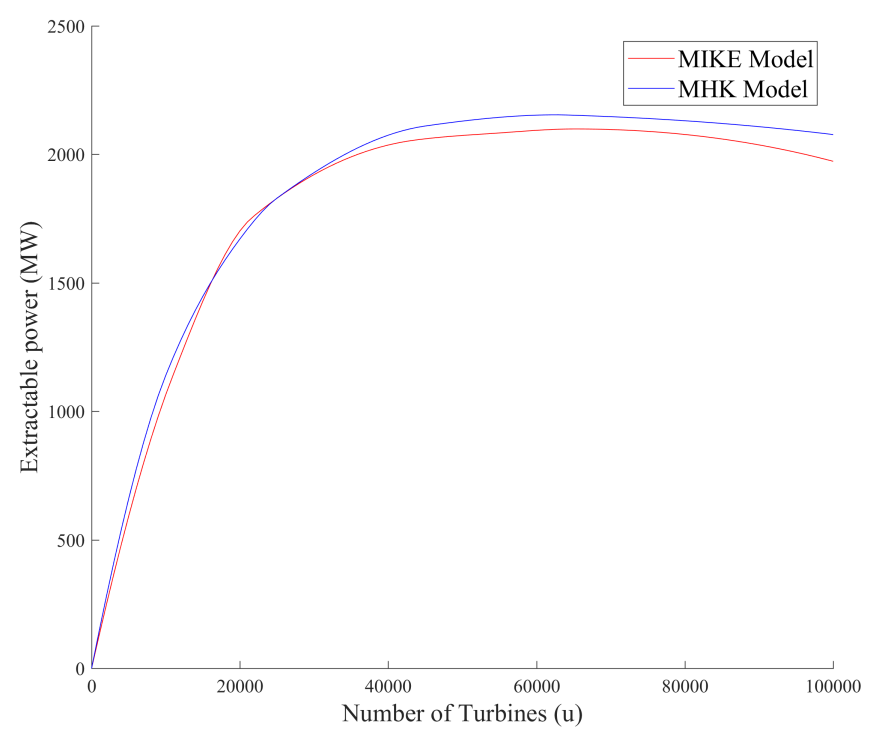

Figure 2: Predicted extractable power as a function of number of turbines

[27] with a maximum difference of extractable power less than $5 \%$. This difference may 
occur as the channel here were discretised with a finer unstructured mesh of 10855 elements compared to the 1140 elements in the (FVCOM) model [27]. The results showed that the maximum tidally extractable power was $2099 \mathrm{MW}$, in line with the analytical solution of 2004 MW derived using the Eq.6 [35, 27]. The model result was only higher of $4 \%$ than the analytical model, which is in the range of $+-10 \%$ variation prescribed by [35] .

$$
P_{\max }=0.22 \rho g a Q_{\max }
$$

where $a$ is the tidal amplitude, $g$ is the gravity acceleration and $Q_{\max }$ is the maximum volume flux in the tidal channel with no turbines.

\subsection{Formulae for sediment transport rates}

For the sediment transport module two formulae were used and tested: Van Rijn (VR) and Engelund \& Fredsøe (EF). The bed load formula for each approach is shown in Appendix A. The major difference between the two methods is the calculation of the bed layer thickness, the Shields parameter, the exponent applied to input velocity and the calculation of the friction velocity. EF considers the bed layer thickness equal to twice d50 (median grain size), whereas Van Rijn uses the saltation height with a minimum of twice d50. The Shields parameter $\theta_{c}$ is always constant for EF but varying upon $D_{*}$ (dimensionless particle parameter) in VR formulae and so depending on the grain size. In this study $\mathrm{d} 50$ is constant, so $\theta_{c}$ is equal to 0.044 in the tidal channel $(\operatorname{depth}=60 \mathrm{~m})$ for VR equations. Different ranges of exponents are applied to the input velocity for $S_{b l}$ : 1 for EF, 4.1 for VR. The approach to calculate the friction velocity are both functions of $\mathrm{v}, \mathrm{h}$ and $\mathrm{d} 50$ but with a different constant. The influence of these differences in the sediment transport equations is investigated in this work.

\subsection{Model Set up}

All models were run for 4 days of simulation time (with an additional $12 \mathrm{~h}$ spin up to avoid any start up transients) with a timestep of 600s. The mesh resolution of the domain varied based on distance to the simulated tidal farm. Near the models boundary elements of up to $2 \mathrm{~km}$ were used, with resolution increasing in the channel region, from $180 \mathrm{~m}$ to $20 \mathrm{~m}$ (the size of the turbines). The unstructured meshes resulted in 38602 elements, 19733 nodes for the small channel (SC) and 50485 elements, 25850 nodes for the long channel (LC) models. The grain size was constant and set up to 300um ( median sand) as in [5], based on anterior modelling studies in these high energetic flow sites [36, 28, 29] and preliminary insitu cores in Banks Strait, Tasmania. Median sand characterises most of the seafloor of tidal energy sites [37]. The layer thickness was set up with the default parameter in MIKE (infinite source of sediment). For 3D simulations the mean velocity component used as an input for the sediment transport rates can be calculated in two ways: depth-averaged velocity (DAV) from the hydrodynamic module or derived from the bottom stress value given by the hydrodynamic module (Eq.7):

$$
\bar{V}=\sqrt{\tau_{b} / \rho c_{f}}
$$


where $\tau_{b}$ is the bottom stress value and $c_{f}$ is the drag coefficient. Here the mean velocity is derived from the bottom stress value. This choice is driven by the conclusion of a previous study between the two methods where the 3D using bottom stress value better captured the acceleration near the seabed than the $3 \mathrm{D}-\mathrm{DAV}$ which was very close to the $2 \mathrm{D}$ model (less than $4 \%$ difference [5]). Changes in 3D compared to the 2D setup include the vertical layers and the bed resistance where the roughness height was used and calculated from Manning's number (Eq.8) with $k_{s}$ the roughness height:

$$
M=\frac{25.4}{k_{s}^{\frac{1}{6}}}
$$

The model domain was decomposed into 19 vertical layers to have more details under the turbines and near the seabed. For the simulations implemented with turbines, the configuration of a tidal farm of 500 turbines with a spacing about 10 diameters longitudinally as in [30], and with lines of 50 turbines each were chosen. The parameters for the turbines were as follows: Ct was set to 0.85 , the diameter of the turbine was set to $20 \mathrm{~m}$, and the hub height was set to $17 \mathrm{~m}$, as these values are commonly used in the literature and represent a generic turbine [30, 38]. The tidal farm was centered in the middle of the tidal channel (Fig.3). Two experiments were performed in this paper and are summarised in Fig.4.

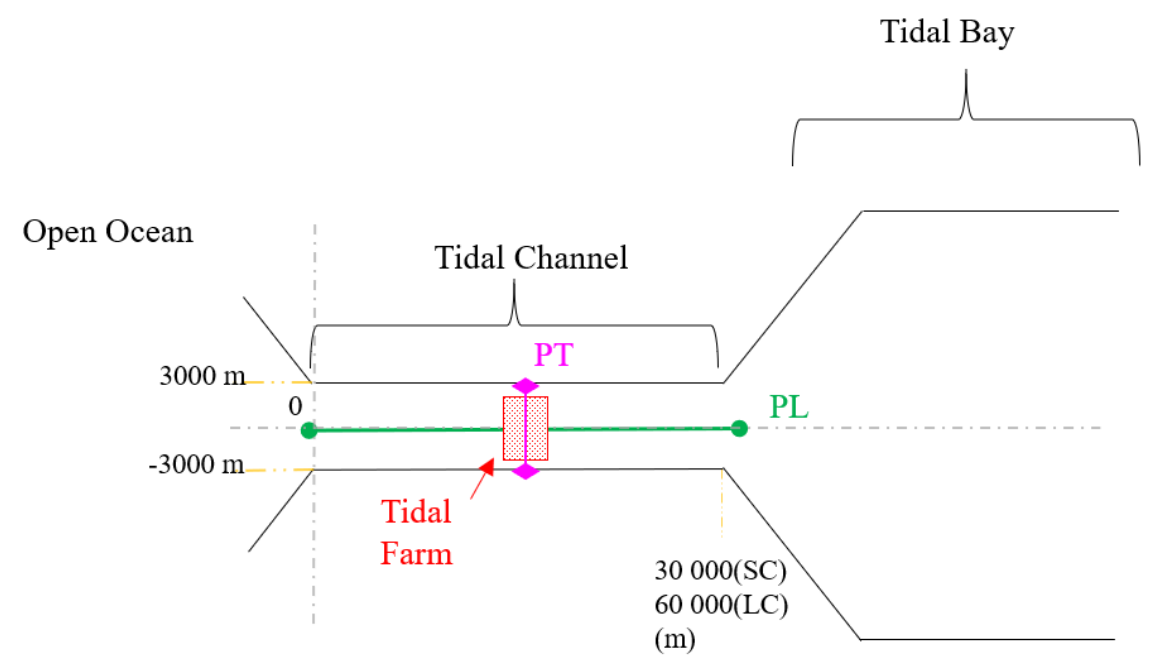

Figure 3: Domain schematisation (not to scale) with the location of longitudinal profile PL and transversal profile PT

\section{Results and Discussion}

Simulations were performed comparing the influence of spatial extent and sediment transport formulae with pure current only. 

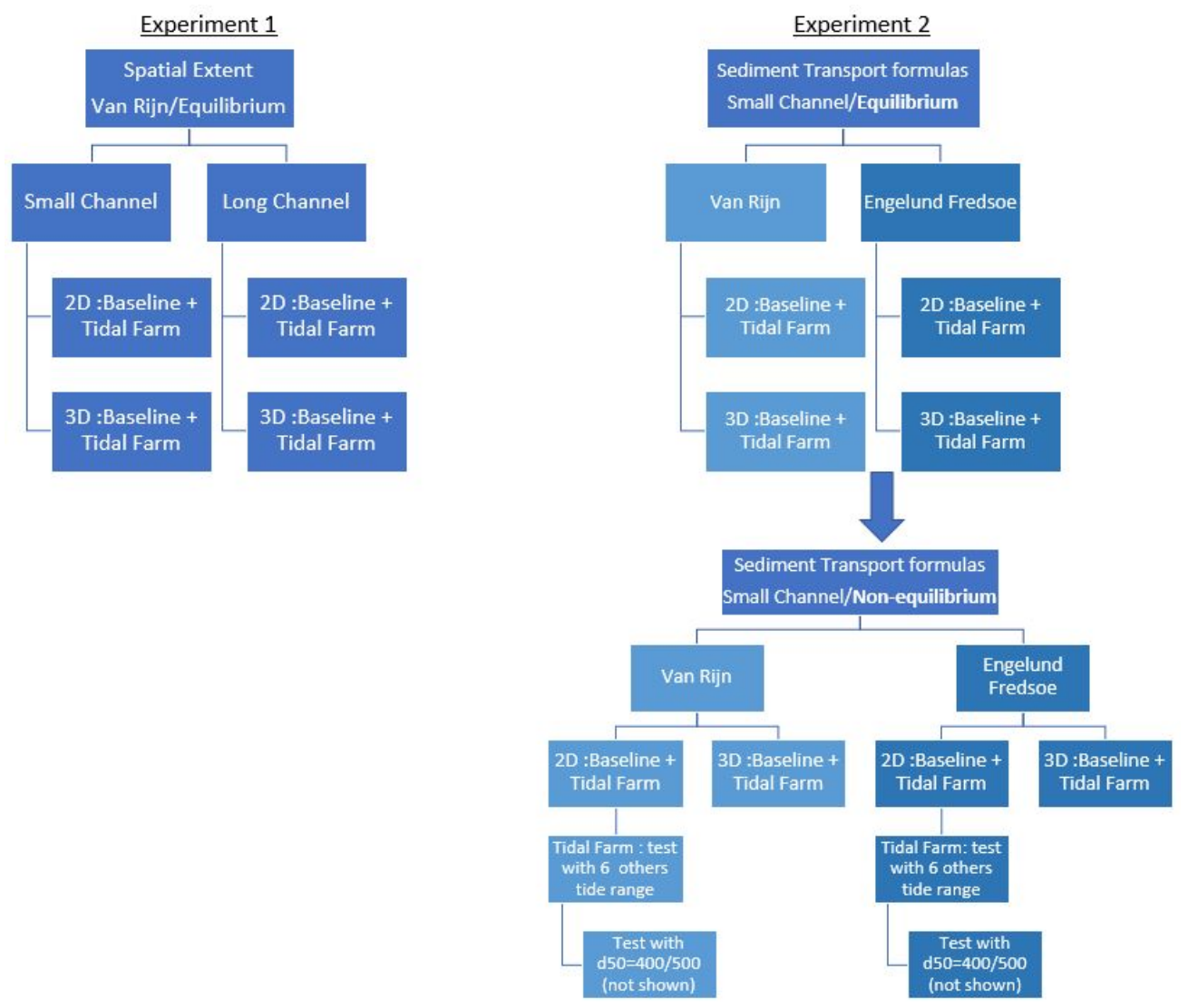

Figure 4: Flow chart of the several simulations

\subsection{Spatial extent : effects on sediment dynamics}

Simulations were performed in 2D and 3D in both channels with currents as the only dominating hydrodynamic forcing. The Van Rijn formula with equilibrium condition was chosen for the calculation of sediment transport rates. Examination of results found differences in bed level changes along a longitudinal profile (location on Fig. 3) between the two models as shown in Fig.5.

In the small channel the difference between 2D and 3D was significant at the location of the tidal farm: with differences found of $1.56 \mathrm{~m}$ for $3 \mathrm{D}$ against $0.48 \mathrm{~m}$ for $2 \mathrm{D}$ when compared to the baseline case. The average difference along the profile PL was $0.19 \mathrm{~m}$ and it reached $0.56 \mathrm{~m}$ inside the tidal farm with a maximum of $1.80 \mathrm{~m}$. The variations in bed levels between the $2 \mathrm{D}$ and 3D were reduced away from the tidal farm and were disturbed at the boundaries of the tidal channel by the open ocean and the tidal bay, as seen around value 50 and 450 in Fig 5 . The major difference in bed level change was in the tidal farm region up to +/$1.5 \mathrm{~m}$ difference found, reducing to $10 \mathrm{~mm} 9 \mathrm{~km}$ from the tidal farm. The channel boundaries influence the far field effect in the small channel that is why a longer channel was also studied.

The longer channel results in lower current speeds and reduced variations in the bed level change compared to the small channel. At the location of the tidal farm the trends in the 
bed level change were the same as those in the small channel, however at the boundaries of the tidal channel the variations between $2 \mathrm{D} / 3 \mathrm{D}$ were negligible. This is shown in Fig 6 where the far field average difference is $0.37 \mathrm{~mm}$ between the $2 \mathrm{D}$ and $3 \mathrm{D}$ models. For both the small and long channel the 3D model captures more information on the flow around the tidal farm than the 2D model due to the vertical resolution of the 3D model. Greater sediments accumulation was found in the 3D tidal farm model and a new zone of erosion appeared at the extremity of the farm as a result of the better capture of the flow acceleration near the seabed at the approach of the turbines (Fig 5). To assess the influence of a tidal farm in the far field, the long channel is recommended for any future baseline sediment studies.
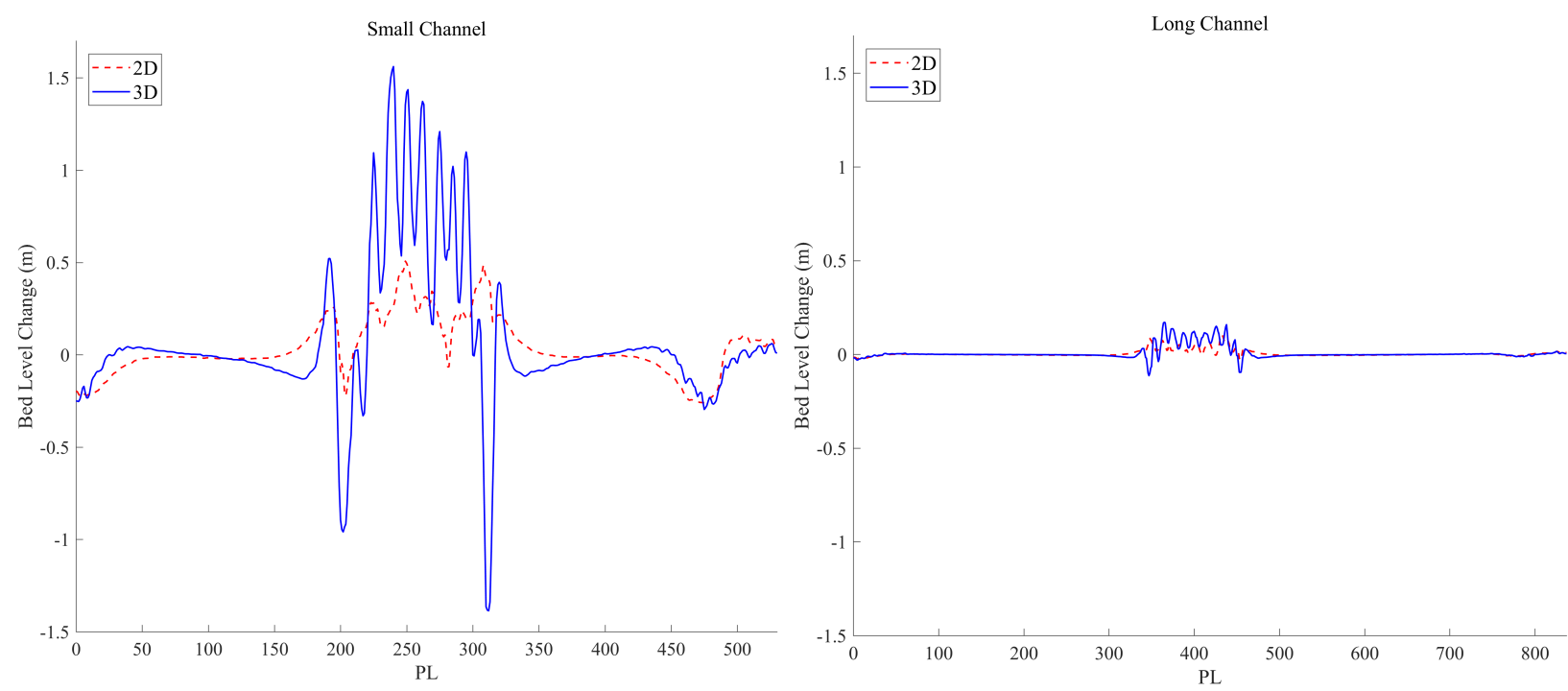

Figure 5: Comparison of bed level changes for $2 \mathrm{D} / 3 \mathrm{D}$ simulation with tidal farm ( $\mathrm{T}=4$ days) for PL location on Fig 3 )

The 2D simulation was 9 times faster than the 3D model, with run times being faster by almost a factor of 10 ( $11 \mathrm{~h}$ in 2D compared to 100 hours in 3D). Although a 2D hydrodynamic model is commonly applied for sediment transport modelling, most of the information about the vertical structure of the flow is lost in the depth-averaging process. A 3D model, though more complex and CPU intensive, simulates the vertical distribution of currents in the water column needed to model sediment dynamics and for simulating underwater structures. For a preliminary environmental assessment of a potential site for tidal energy, the authors recommend that $2 \mathrm{D}$ modelling approaches are suitable given both the reduced computational cost and the fact that differences between the 2D and 3D models become negligible far away from the tidal farm. However, to examine near field results, 3D models are required which is in accordance with the statement of [39] for smaller scale. The influence of the tidal farm on bed level change is localised at the vicinity of the tidal farm and extend up to $9 \mathrm{~km}$ from the array. These results are similar to realistic cases: using 2D modelling, Robins [29] found that the influence of the tidal turbines will be comparable to the natural variability for the 


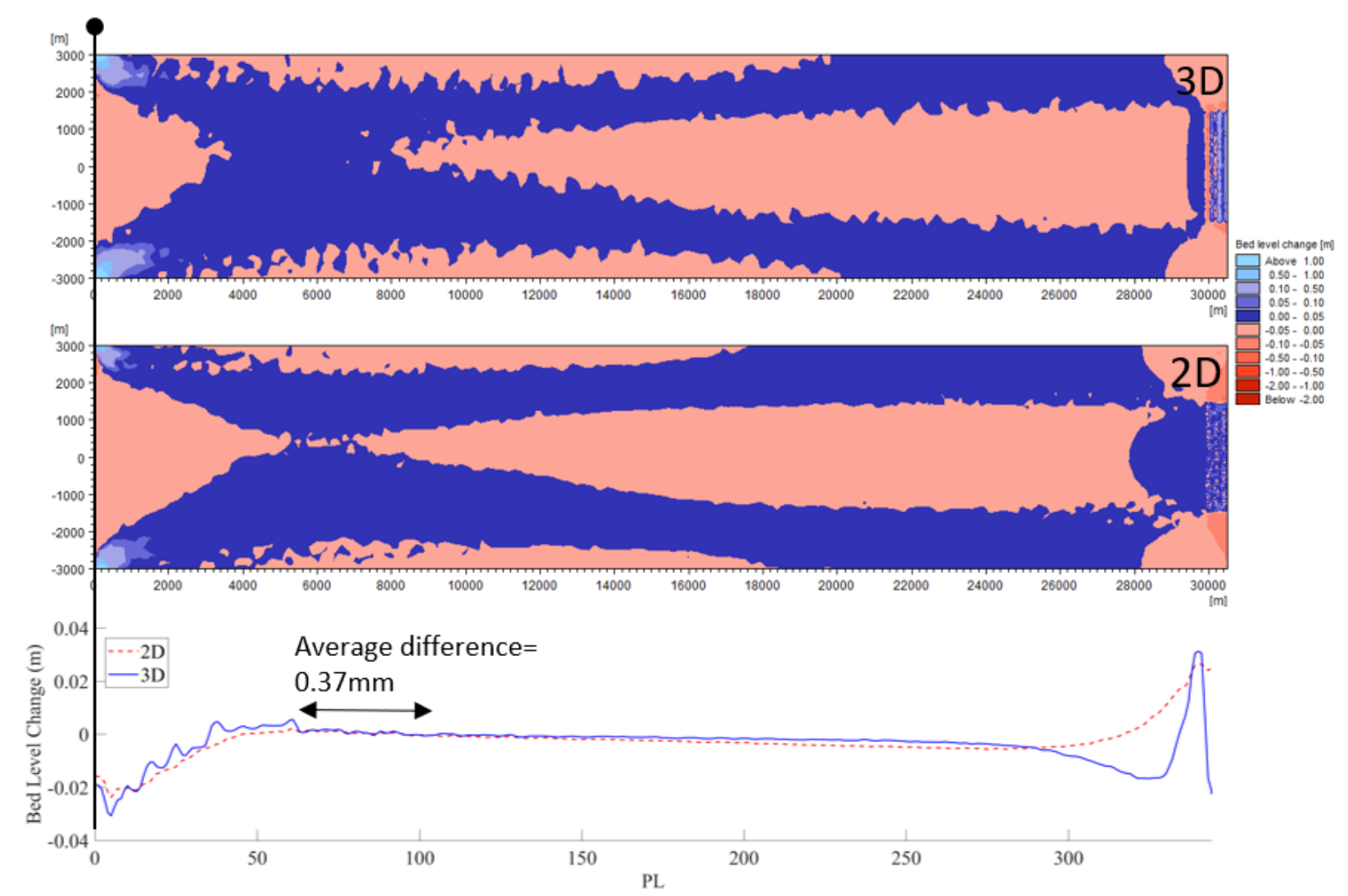

Figure 6: Comparison of bed level changes determined by 3D and 2D simulations of a tidal farm ( $\mathrm{T}=4$ days) in long channel with Van Rijn formula.

dynamic of sediments $10 \mathrm{~km}$ from the array for the Skerries in the Irish Sea and, Haverson [38] in Ramsey Sound observed that the influence of energy extraction on bed shear stress will not occur beyond $12 \mathrm{~km}$ from the tidal farm.

\subsection{Sediment transport formulae}

\subsubsection{Equilibrium conditions 2D/3D}

The performances of two sediment formulae: Van Rijn (VR) [12, 13] and Engelund \& Fredsøe (EF) [10] with equilibrium conditions have been analysed in the small channel.

Simulation results for the baseline case found larger difference in bed level change between VR and EF models: an average difference of $92 \mathrm{~mm}$ for PL in 2D and $62 \mathrm{~mm}$ for 3D (Fig. 7). The comparison of the bed level after 4 days revealed a significant difference between the two models around the location of the tidal farm, with the EF Equilibrium model showing a very rough bed level compared to VR Equilibrium where the mesh is refined. The EF Equilibrium model was less stable and more sensitive to the mesh density. The current speed mean values for the EF Equilibrium baseline case were approximately 1\% higher than that found in the VR Equilibrium baseline case. 

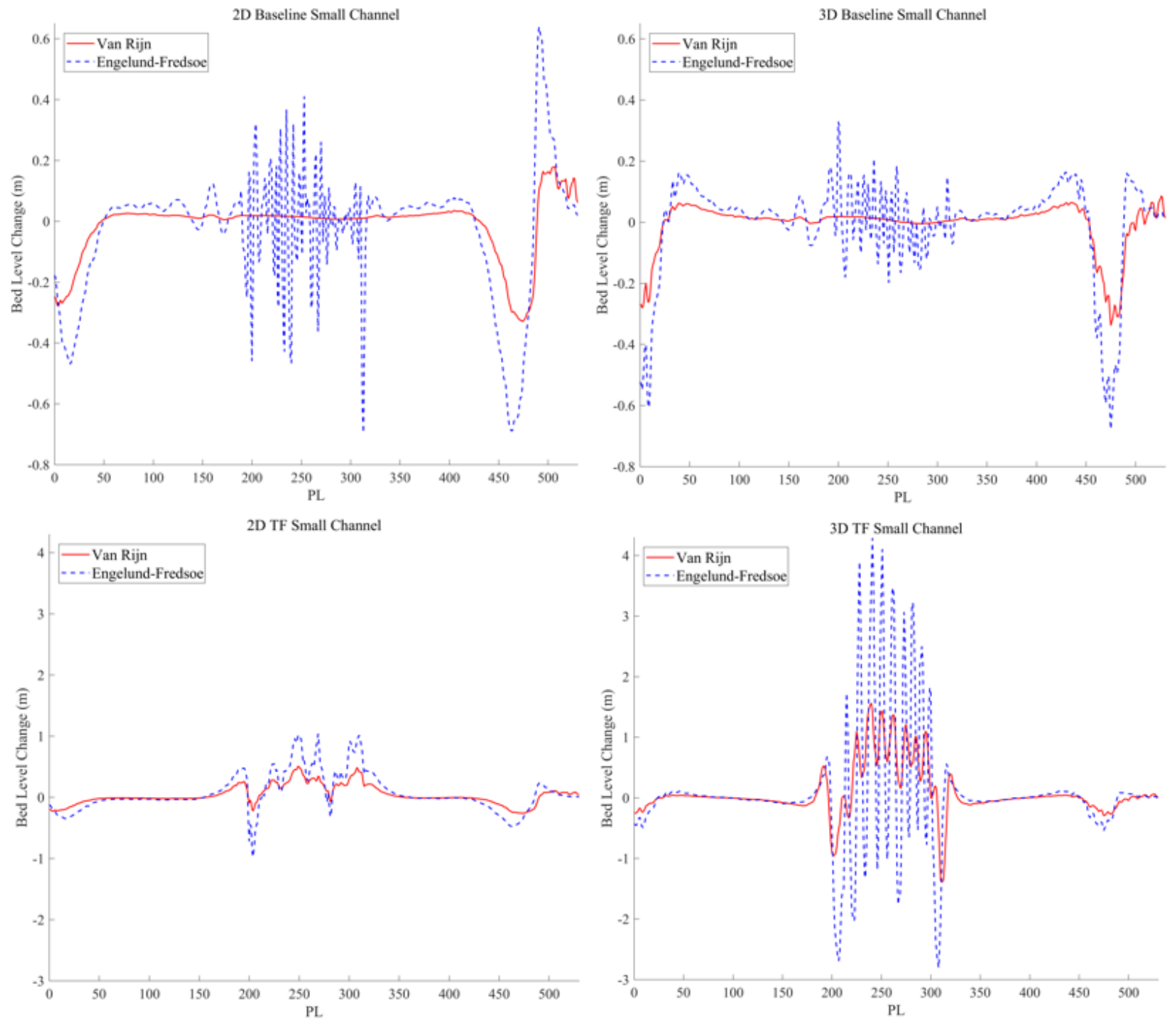

Figure 7: Comparison of bed level changes for Small Channel Baseline and Tidal Farm for PL at T=4 days at Equilibrium conditions

For simulations with the tidal farm, the average difference of bed level change for PL profile in 2D was $109 \mathrm{~mm}$ (199mm for the profile PT) and in 3D 292mm for PL with an average of $1 \mathrm{~m}$ difference in the tidal farm (Fig 7). The VR Equilibrium model found less erosion at the top and bottom of the tidal farm and inside the tidal farm when compared to the EF Equilibrium model results for both 2D and 3D (Fig. 8). The discrepancy between the two formulae was found to be larger when comparing results obtained from 3D models. Between each line of turbines, a zone of erosion appeared in the EF model. Bed level change factors of an average of 2 were found in the far field, with changes of up to 6 inside the tidal farm, with the EF Equilibrium model predicting increased accretion and erosion in the tidal farm region when compared to the VR model. The statistical mean of current speed in $2 \mathrm{D}$ 

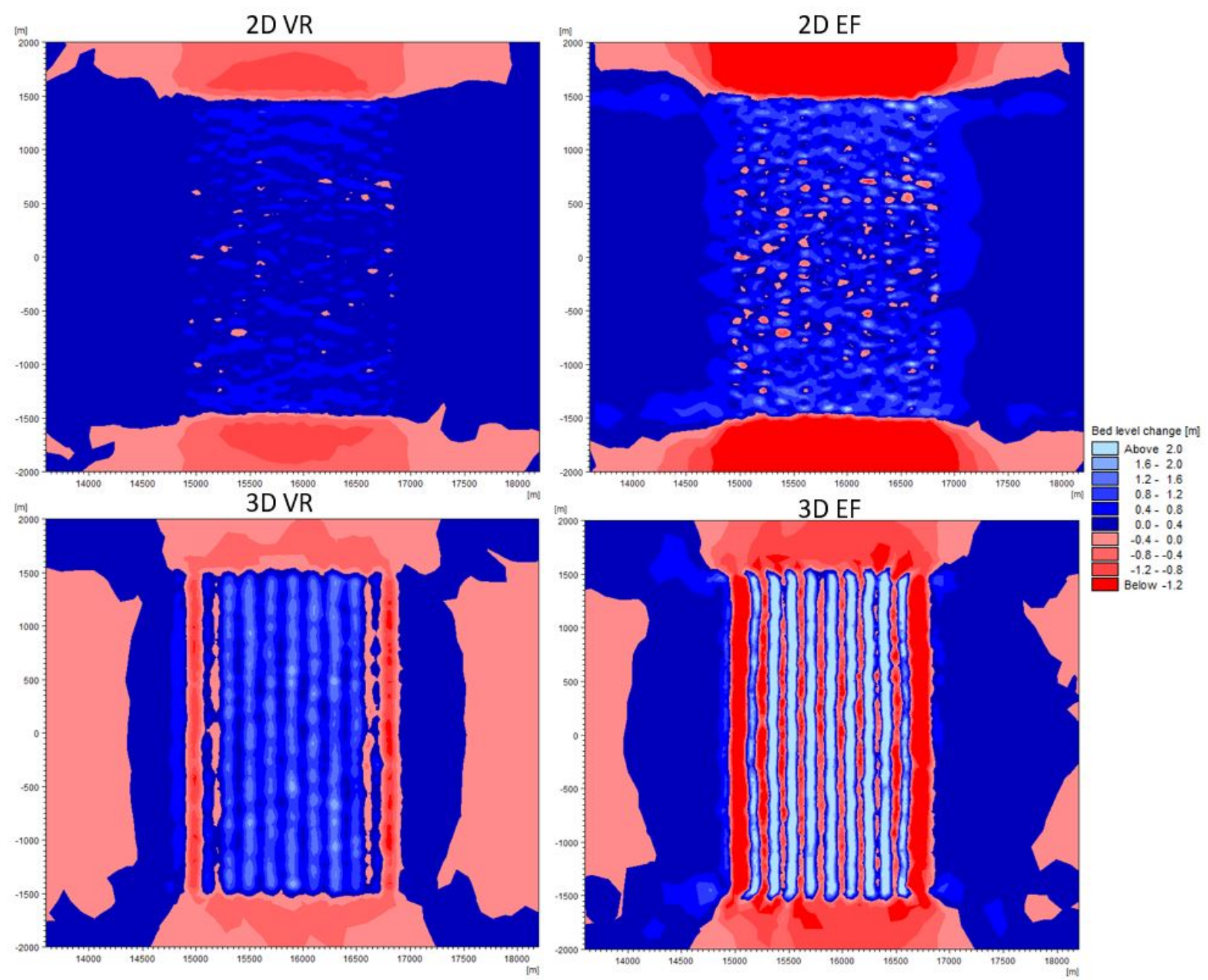

Figure 8: Comparison of bed level changes between VR Equilibrium and EF Equilibrium formulae for Small Channel $\mathrm{TF}$ in $2 \mathrm{D}$ and $3 \mathrm{D}$ at the location of the tidal farm at $\mathrm{T}=4$ days

at the location of the tidal farm showed little differences between the two formulae (Fig 9 ). When EF Equilibrium was used, the current speed was higher at the top and bottom of the tidal farm, and slightly higher inside the tidal farm. These differences can be explained by the coupled model HYD-ST, where the morphology of the bed level is included to the calculation of the hydrodynamic module. A rough bed generates more turbulence and thus more bed shear stress. The EF Equilibrium model results for the baseline appeared to be influenced by the mesh size as shown in Fig.7, suggesting that it overestimates bed level change at the location of the tidal farm.

Simulations were also performed with a coarser mesh $(100 \mathrm{~m}$ and $500 \mathrm{~m})$ in the tidal farm to examine the influence of mesh density on the bed level change. The results of the 2D and 3D EF Equilibrium baseline models showed a mesh dependency between mesh resolution and bed level change. The authors therefore conclude that the equilibrium approach with $\mathrm{EF}$ formulae is not suitable for tidal turbine sediment studies, as it appears to be highly 
influenced by mesh resolution.

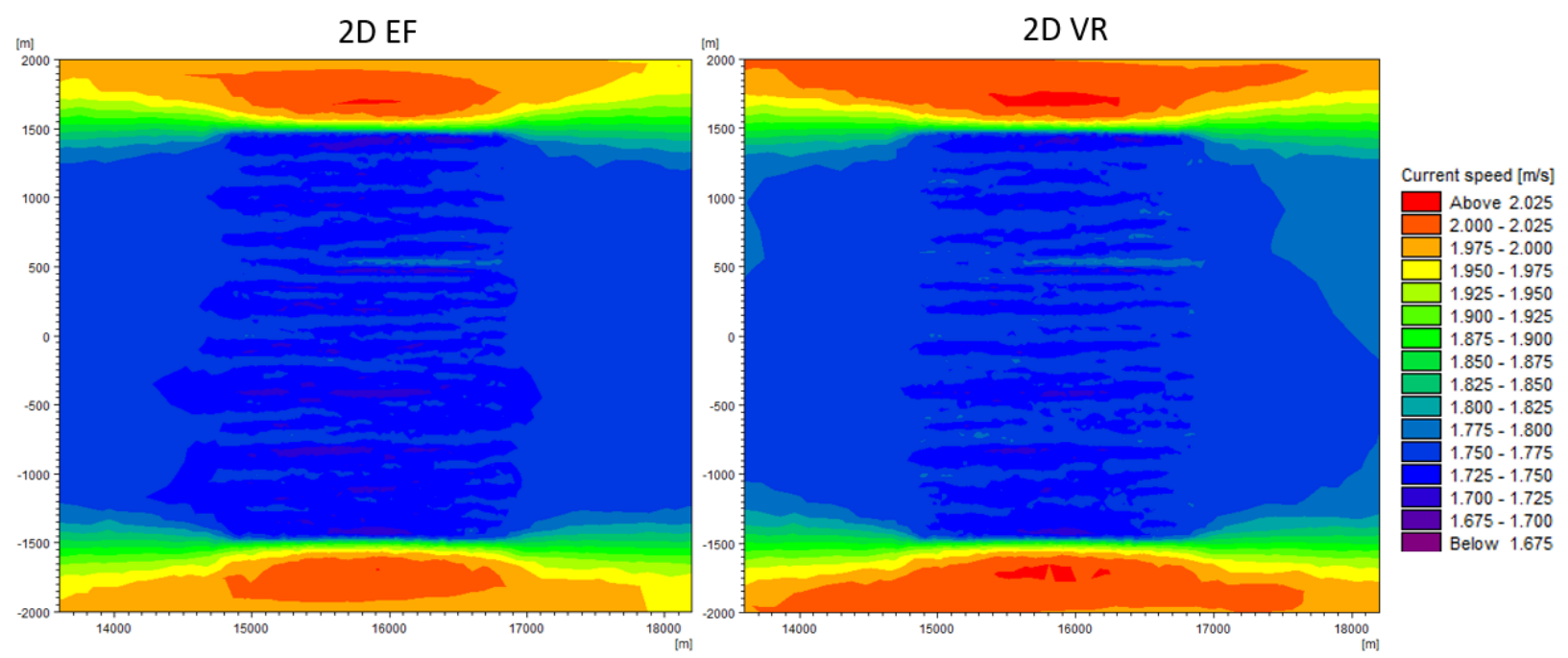

Figure 9: Comparison of Statistical mean Current speed for the Small Channel TF in 2D at the location of the tidal farm in Equilibrium mode for VR and EF showing slight differences

\subsubsection{Non-Equilibrium condition 2D/3D}

As the EF Equilibrium models' predictions of bed level change were found to be highly mesh dependent, the Non-Equilibrium condition was also tested in the small channel to determine if this approach was as equally dependent on mesh size.

Simulation results for the baseline 2D model with EF Non-Equilibrium formulae showed different results when compared to EF Equilibrium, with the Non-Equilibrium approach more stable and not dependent on the mesh size (Fig.10). For VR simulations including a tidal farm, the difference between equilibrium and non-equilibrium was not significant, with differences of approximately $15 \mathrm{~mm}$ along profile PL in 2D and $72 \mathrm{~mm}$ in 3D (Fig 10). The 3D VR Equilibrium model was found to slightly overestimate the bed level change when compared to the VR Non-Equilibrium model with an average height difference in the tidal farm of $0.24 \mathrm{~m}$, a result not found in the $2 \mathrm{D}$ model. Considering the advection/diffusion of the suspended sediment, the non-equilibrium approach tends to deposit less sediment on the bed at the location of the tidal farm as expected.

In the non-equilibrium mode models with tidal farm, comparisons between the two formulae showed higher rates of bed level change for the EF Non-Equilibrium formula. Results along the profile PL revealed an increase in accretion and erosion inside the tidal farm for the EF Non-Equilibrium. The average difference of bed level changes between the two formulae along the profile PL was $100 \mathrm{~mm}$ and $191 \mathrm{~mm}$ for the profile PT in 2D. In 3D, the values along the profile PL were similar with $93 \mathrm{~mm}$ of average difference based on the mean current speed at the bottom layer being $1 \%$ higher for EF Non-equilibrium, generating slightly higher bed load rates (Fig,11). The analysis of current speed time-series in 

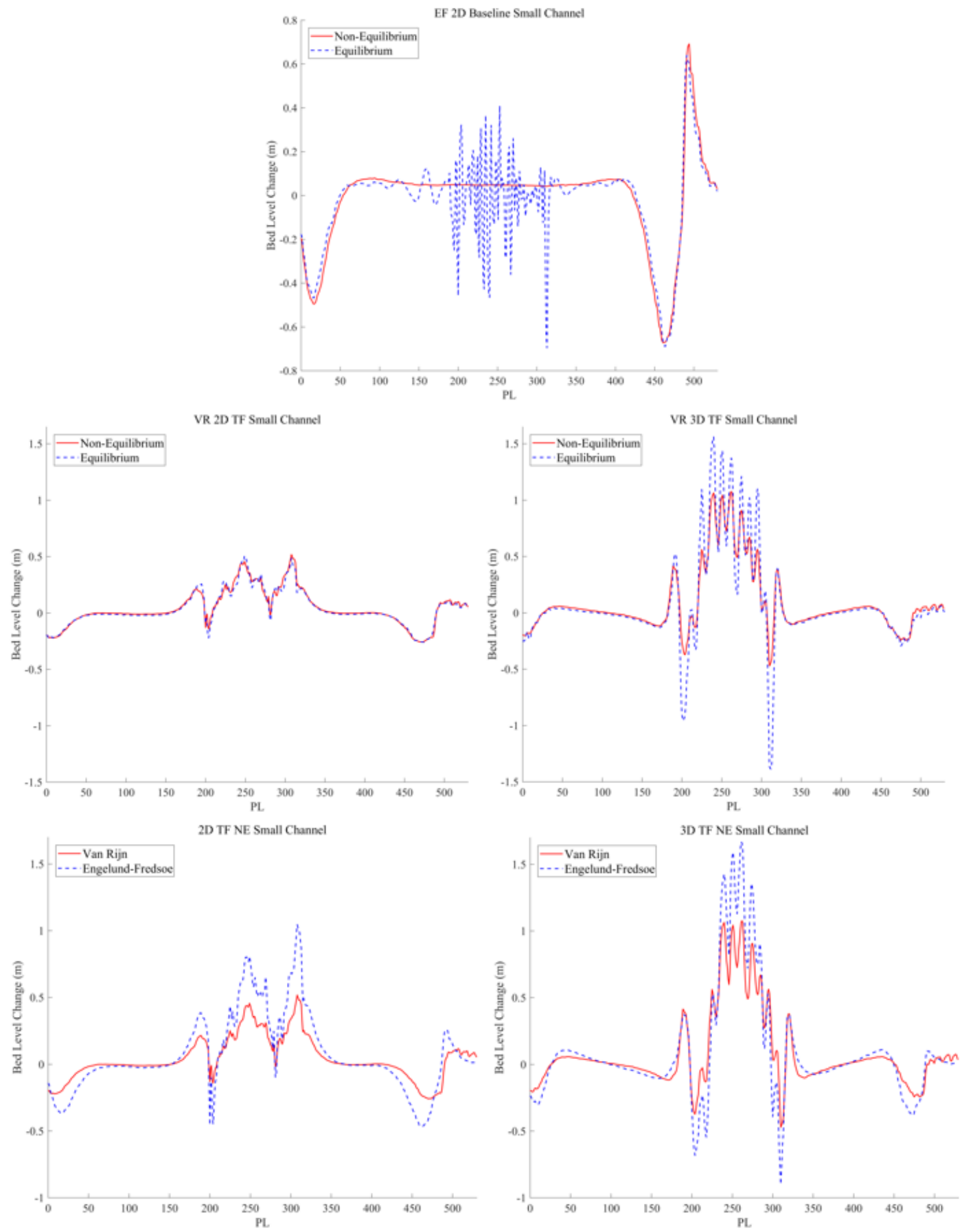

Figure 10: Comparison of bed level changes for EF Baseline in 2D, VR Tidal Farm formulae for 2D and 3D, and VR/EF Non-Equilibrium comparison in $2 \mathrm{D}$ and $3 \mathrm{D}$ in the small channel at PL at $\mathrm{T}=4$ days 
2D and 3D for each model revealed similar disparity for a point inside the tidal farm: $0.6 \%$ for $2 \mathrm{D}$ and $1.11 \%$ for $3 \mathrm{D}$ (Fig 12 ). The actual sediment concentration in the water column is higher than the equilibrium concentration for the EF Non-Equilibrium model compared to the VR Non-Equilibrium model allowing more sediment deposition inside the tidal farm. The EF Non-Equilibrium formulae generated the largest bed level change inside the tidal farm. Soulsby [97] showed that there is a factor of 2 between the results of different sediment transport formula, and there can be uncertainty of sediment transport rates up to a factor of 5 [20]. Here for the non-equilibrium conditions in 3D the factor reveal a difference factor of about 1.9 for the total load transport rates and 1.4 for bed level changes, illustrating the degree of uncertainty in determining sediment transport rates.
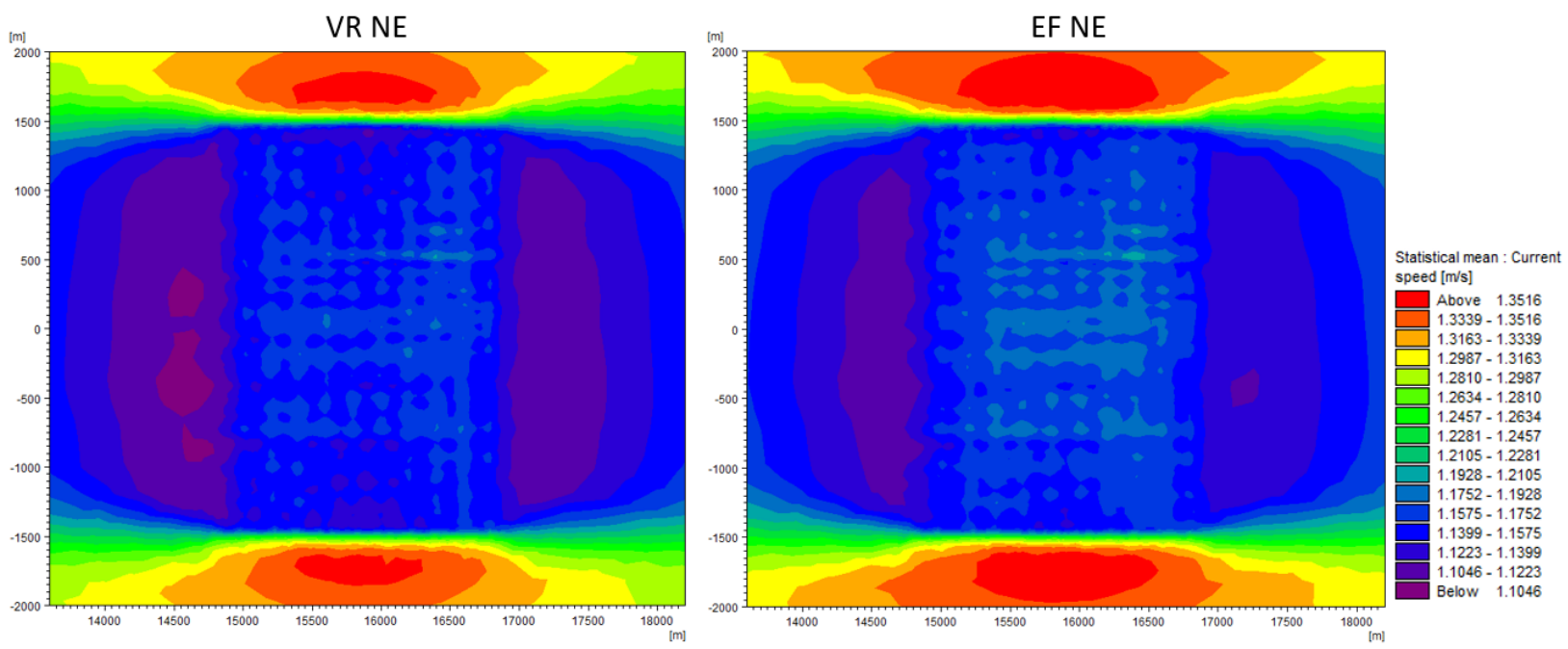

Figure 11: Mean current speed for the bottom layer in each model
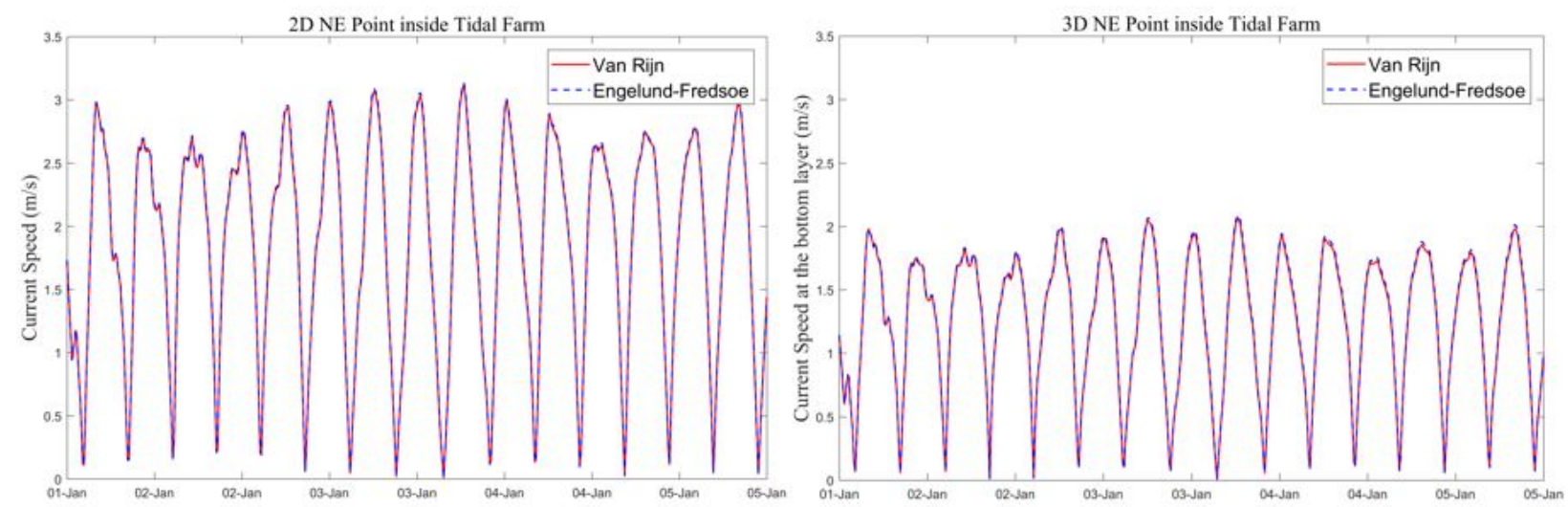

Figure 12: Comparison of Current speed Time Series in 2D and 3D for each model for a point inside the tidal farm 

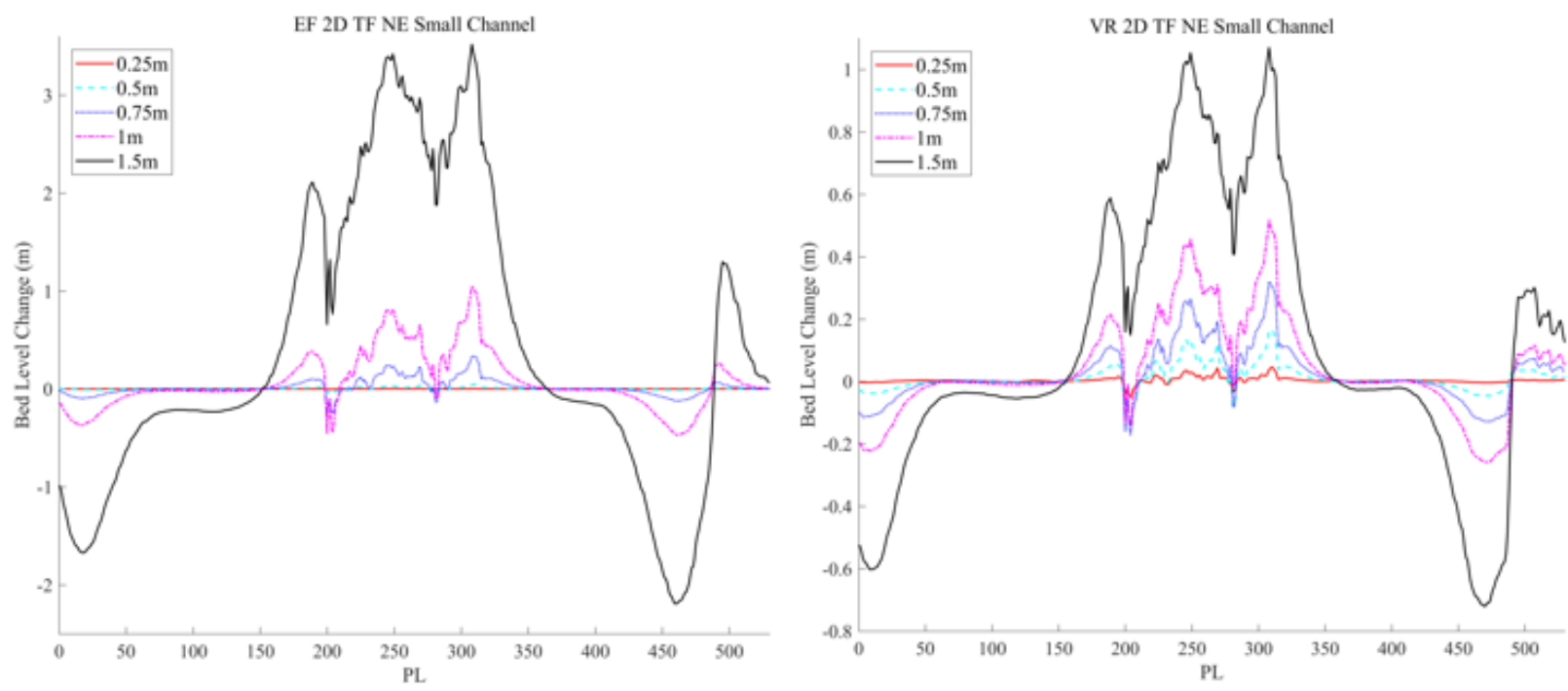

\begin{tabular}{ccccccccc}
\hline Behaviour of BLC in TF & $0.25 \mathrm{~m}$ & $0.5 \mathrm{~m}$ & $0.75 \mathrm{~m}$ & $0.85 \mathrm{~m}$ & $1 \mathrm{~m}$ & $1.25 \mathrm{~m}$ & $1.5 \mathrm{~m}$ \\
\hline $\mathrm{d} 300$ & $\begin{array}{l}\mathrm{EF}>\mathrm{VR} \\
\mathrm{EF}<\mathrm{VR}\end{array}$ & $\mathrm{x}$ & $\mathrm{x}$ & $\sim$ & $\mathrm{x}$ & $\mathrm{x}$ & $\mathrm{x}$ & $\mathrm{x}$ \\
\hline $\begin{array}{l}\text { Mean Current } \\
\text { speed (m/s) }\end{array}$ & 0.84 & 1.23 & 1.54 & 1.64 & 1.78 & 2 & 2.21 \\
\hline
\end{tabular}

Figure 13: Difference of bed level changes between several tidal range for Small Channel TF at PL at T=4 days in non-equilibrium conditions in $2 \mathrm{D}$

Further tests were conducted in 2D including the implementation of a tidal farm for different tide ranges $(0.25 \mathrm{~m}, 0.5 \mathrm{~m}, 0.75 \mathrm{~m}, 0.85 \mathrm{~m}, 1.25 \mathrm{~m}, 1 \mathrm{~m}$ and $1.5 \mathrm{~m})$ to investigate the impact of the two sediment transport models at different current speeds. Bed level changes for the EF Non-Equilibrium formulae were usually lower than for the VR Non-Equilibrium formulae when the current speeds were smaller than $1.54 \mathrm{~m} / \mathrm{s}$ (Fig. 13$)$. The value of bed level change was similar for both formulae for current speeds equal to $1.54 \mathrm{~m} / \mathrm{s}$ with the tidal range of $0.75 \mathrm{~m}$. However, when current speeds were higher than $1.78 \mathrm{~m} / \mathrm{s}$, the EF Non-Equilibrium model reported an increased bed level change almost three times higher than the VR Non-Equilibrium value (Fig 14). Additional simulations were carried out with finer grain sizes $\left(d_{50}=400,500 \mu \mathrm{m}\right)$ : the results were similar, above a current speed threshold the EF formulae generated a large difference in the value of bed level changes. The VR Non-Equilibrium formulae exhibited smaller changes with all of the simulated tidal ranges compared to results discussed in [19]. This suggests that the VR Non-Equilibrium model has a lesser dependency on velocity and grain size than the EF Non-Equilibrium. The EF NonEquilibrium models were very sensitive to current speed changes leading to very high values of bed level changes for high current velocities. The simulations in these studies reinforce the assumption that VR formulae are considered best practice and reveal that the EF formulae are more sensitive to basic physical properties than the VR formulae. This analysis highlights 


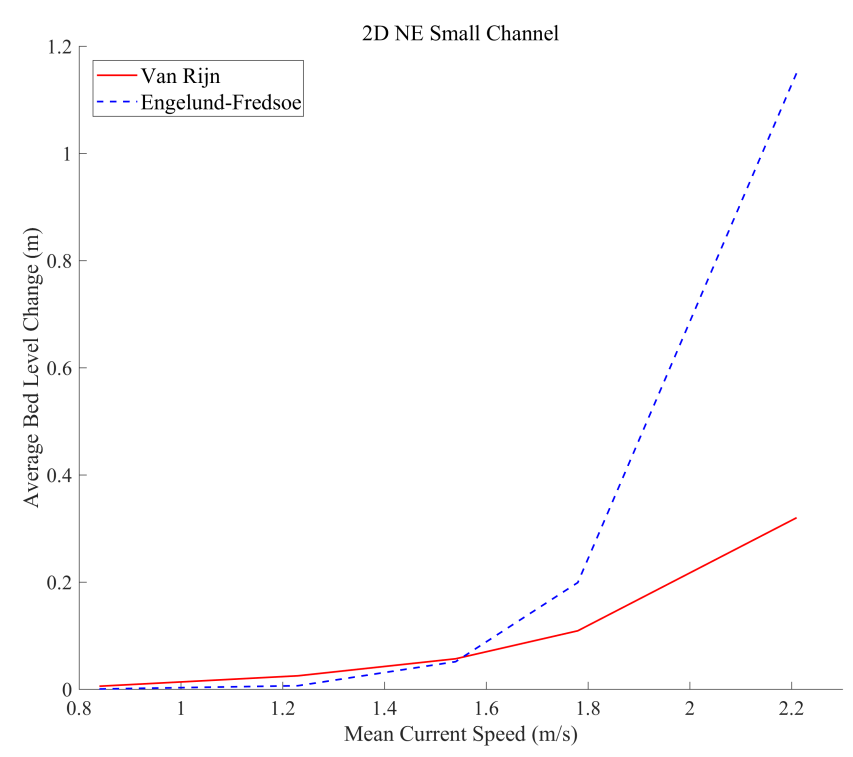

Figure 14: Average of bed level changes for PL at $\mathrm{T}=4$ days against Mean current speed in tidal channel for $\mathrm{SC} \mathrm{TF}$

the uncertainty between the different formulae and underlines the importance of evaluating sediment transport formulae on the basis of field data before making a choice of the approach to model sediment transport.

\subsubsection{Summary}

In 2D models, smaller differences have been observed for VR formulae between equilibrium and non-equilibrium conditions. The 3D model reveals that in equilibrium condition, the VR formula tend to have higher sediment transport rates in the tidal farm compared to the non-equilibrium one. In the equilibrium model sediments react instantly with the flow, whereas in the condition of non-equilibrium a lag time effect is introduced with the actual conditions. With non-equilibrium conditions the bed level change is linked to the difference between the removal rate of sediment into the current and the accumulation of sediment on the seafloor. The simulation with equilibrium conditions fails to take the time lag into account and might overestimate sediment transport rates, which is reproduced in the MIKE model. The computational costs of the different approaches for $2 \mathrm{D}$ are listed in Table 2 and show that the non-equilibrium condition runs are slightly slower for both formulae. The authors recommend that the non-equilibrium condition is relevant to evaluate morphological changes in high energy tidal sites, even with a slightly higher computational cost. A closer look at the bottom layer in the 3D models showed that near bed velocities were reduced to $7.33 \%$ in the simulations including the implementation of a tidal farm compared to the baseline model of the VR Non-Equilibrium formula (Fig.15). The layer considered was just above the seabed and below the rotor plane of tidal turbines. This reduction is an important fact which could lead to significant change for the morphological change, especially for 


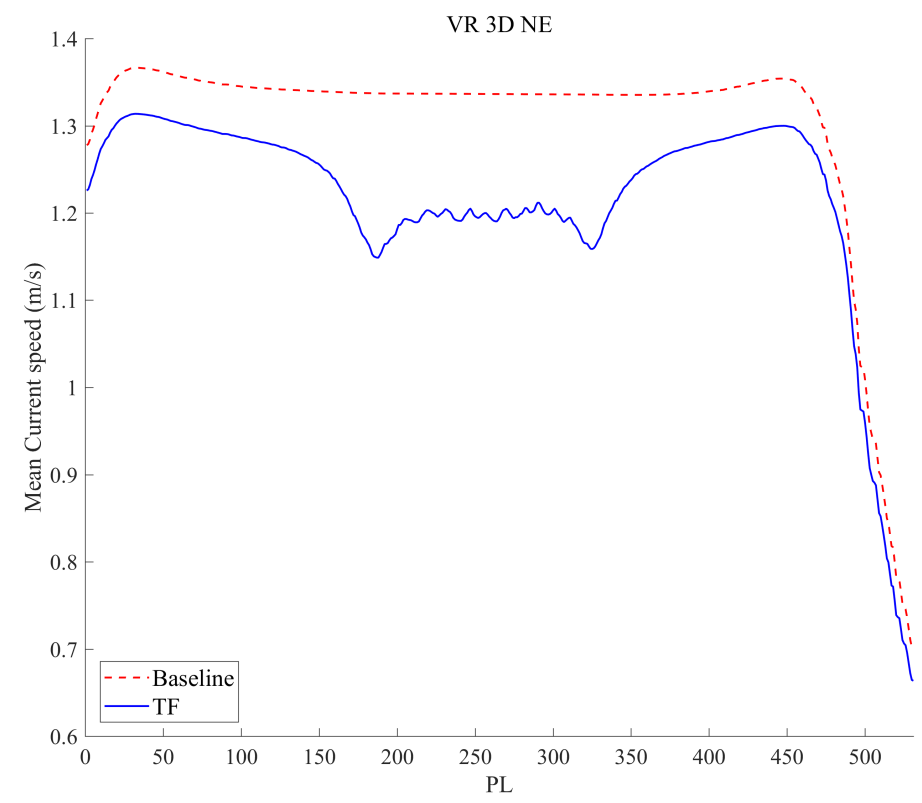

Figure 15: Comparison of Mean Current speed between VR Non-Equilibrium baseline and VR NonEquilibrium TF for the layer just above the seabed.

sandbanks as indicated by [40].

Table 2: Computational costs of the different approaches in 2D for 1 day simulation period

\begin{tabular}{lllcc} 
& \multicolumn{2}{c}{ Equilibrium } & \multicolumn{2}{c}{ Non-Equilibrium } \\
& EF & VR & EF & VR \\
\hline Length of Run for & $4 \mathrm{~h}$ & $4 \mathrm{~h}$ & $4 \mathrm{~h} 25$ & $4 \mathrm{~h} 10$ \\
1 day simulation period & & & & \\
\hline
\end{tabular}

The MIKE 21/3 model for combined waves and current is based on the approach of Engelund \& Fredsøe where bed load transport is estimated from the instantaneous Shields parameter with the Engelund \& Fredsøe formulae and suspended load transport is derived from Fredsoe et al. [41. A first analysis of bed load transport formula has been performed here in a simplified environment (using only current as hydrodynamic forcing), showing that caution should be taken to use this formula in the combined wave \& current mode in future studies. The findings of this paper will contribute to understand the performance of the model in a potential candidate site for tidal energy conversion, e.g. Banks Strait, Tasmania. The model results presented here will also help to develop a 2D model for far field and a 3D model for near field simulation for this real-world scenario, allowing the analysis of the influence of tidal farms on sediment and hydrodynamics properties. The advantage of an idealised model is the presentation of a wide range of simplified assumptions necessary to understand the complex phenomena of sediment dynamics. It is an important step before applying the model to real-world conditions with more complex model parameters such as 
bathymetry or coastlines. The studied configuration is idealized and has several limitations: firstly, the channel is greatly simplified as it has no complex bathymetry and exhibits only a uniform sediment grain size and due to unstructured mesh, the domain is not perfectly symmetric. Secondly, the use of an artificial channel only allows a comparison of the state before and after varying the parameters. Thirdly the use of only one layout for the array is simplified to observe the response to the sediment dynamics with the same geometry in a very idealized configuration. The optimization of the arrays is out of the scope of this study. Finally, as [30] mentioned in his studies MIKE3 has not been used for sediment transport models in tidal energy sites. These results should be interpreted with caution and future work in lab experiments or real-world case simulations compared to field data would be useful. To the knowledge of the authors no sediment transport model has been validated in tidal energy sites given the difficulty of measuring sediment transport and therefore lack of sediment data.

\section{Conclusion}

2D and 3D models were used to simulate the influence of a tidal farm on the bed level change in small and long idealised channels. Equilibrium and non-equilibrium conditions were also tested on two sediment transport formulae: Engelund \& Fredsøe and Van Rijn. This benchmark shows that 2D model gives similar results as 3D model for sediment dynamics in far field and the influence of energy extraction will not extend beyond $9 \mathrm{~km}$ of the tidal farm. The authors recommend that 2D modelling approaches are suitable for a preliminary environmental assessment of promising tidal energy sites given both the reduced computational cost and the negligible difference with 3D modelling. However, to have more insight in the near field 3D model are required. In this benchmark the long channel is less sensitive to channel boundaries and should be used for any future baseline sediment work in the far field.

Vigilance should be applied when studying morphodynamic changes due to a tidal farm, as this work has found that different sediment transport formulae lead to significant differences in bed level change predictions, with a difference of 1.4 found between Engelund \& Fredsøe and Van Riijn models. However, despite these differences in the magnitude of bed level changes, the main residual transport circulation was largely unaffected by the choices of the formula. The Engelund \& Fredsøe in equilibrium condition was considered unstable due to mesh dependency and in non-equilibrium condition was sensitive to changes in current speed, suggesting small errors in this parameter could lead to significant error in bed level change prediction. Additionally, the Engelund \& Fredsøe formulae may not be suitable for high energetic sites given the results for strong currents compared to Van Rijn formulae that seems to run more stable. The first priority for tidal developers when assessing environmental impact is thus to have a well calibrated hydrodynamic model to reduce the uncertainty on a possible error in the current speed, and if possible to have field data to evaluate the sediment transport formulae.

This study is the first step of the larger project to examine the influence of a tidal farm in Banks Strait, Tasmania. The future hydrodynamic and sediment transport model developed 
will be calibrated and validated by in situ data (acoustic doppler current profiler, multibeam and sub-bottom data) collected by the AUSTEn project.

\section{Acknowledgement}

The authors would like to thank Dr Yang Zhaoqing for providing data from his paper and are very grateful to Dr Simon Waldman for sharing his scripts to implement tidal turbines in MIKE. Assistance and support from staff at DHI are gratefully acknowledged, especially Méven Huiban. The authors also wish to thank Dr Kate Edwards for her valuable comments. This work, funded by UTAS/NCMEH scholarship, as well as IMAREST award, contributes towards the AUSTEn project. This project is co-funded by the Australian Renewable Energy Agency through the Advancing Renewables Programme (grant G00902), the Australian Maritime College (University of Tasmania), the University of Queensland, CSIRO, our industry partners MAKO Tidal Turbines and SIMEC Atlantis Energy and our international collaborators Prof. Richard Karstens from Acadia University, Canada, and Dr Matt Lewis from Bangor University, UK.

\section{A. Sediment Transport formulae}

The bed load formula for each approach is shown in Table A.1 and suspended load formula in Table A.2. The following symbols are applied: $s$ Relative density of the sediment, $C$ Chezy number, $V$ Velocity, $h$ Water depth, $g$ Acceleration of gravity, $d_{50}$ Median grain size, $d$ Grain diameter, $\nu$ Kinematic viscosity, for $\mathrm{VR} c 0$ is the concentration corresponding to firm packing of the sediment and for EF $\mu_{d}$ is equal to 0.51 (=tan27, dynamic friction coefficient).

Table A.1: Bed load formulae VR and EF

\begin{tabular}{lcc}
\hline & Van Rijn & Engelund Fredsøe \\
\hline Bed Load & $S_{b l}=0.053 \frac{T^{2.1}}{D_{*}^{0.3}} \sqrt{\left.(s-1) g \cdot d_{50}^{3}\right)}$ & $S_{b l}=5 p \cdot\left(\sqrt{\theta^{\prime}}-0.7 \sqrt{\theta_{c}}\right) \sqrt{(s-1) g d_{50}^{3}}$ \\
\hline Parameters & $D_{*}=d_{50}\left(\frac{(s-1) g}{\nu^{2}}\right)^{\frac{1}{3}}$ & $p=\left[1+\left(\frac{\frac{\pi}{6} \mu_{d}}{\theta^{\prime}-\theta_{c}}\right)^{4}\right]^{-\frac{1}{4}}, \theta^{\prime}>\theta_{c}$ \\
& $T=\left(\frac{u_{f}^{\prime}}{u_{f c}}\right)^{2}-1$ & $\theta^{\prime}=\frac{u_{f}^{\prime 2}}{(s-1) g d_{50}}$ \\
\hline $\begin{array}{l}\text { Effective and critical } \\
\text { friction velocity }\end{array}$ & $u_{f c}=\sqrt{\theta_{c}(s-1) g} d_{50}$ \\
& $u_{f}^{\prime}=V \frac{\sqrt{g}}{C^{\prime}}=V \frac{\sqrt{g}}{18 \log \frac{2 h}{d 50}}$ & $u_{f}^{\prime}=\frac{V}{6+2.5 \ln \left(\frac{h}{2.5 d_{50}}\right)}$ \\
\hline$\theta_{c}$ (Shields Parameter) & Following a variation as a function of $D_{*}[26]$ & \\
\hline
\end{tabular}


Table A.2: Suspended load formulae VR and EF

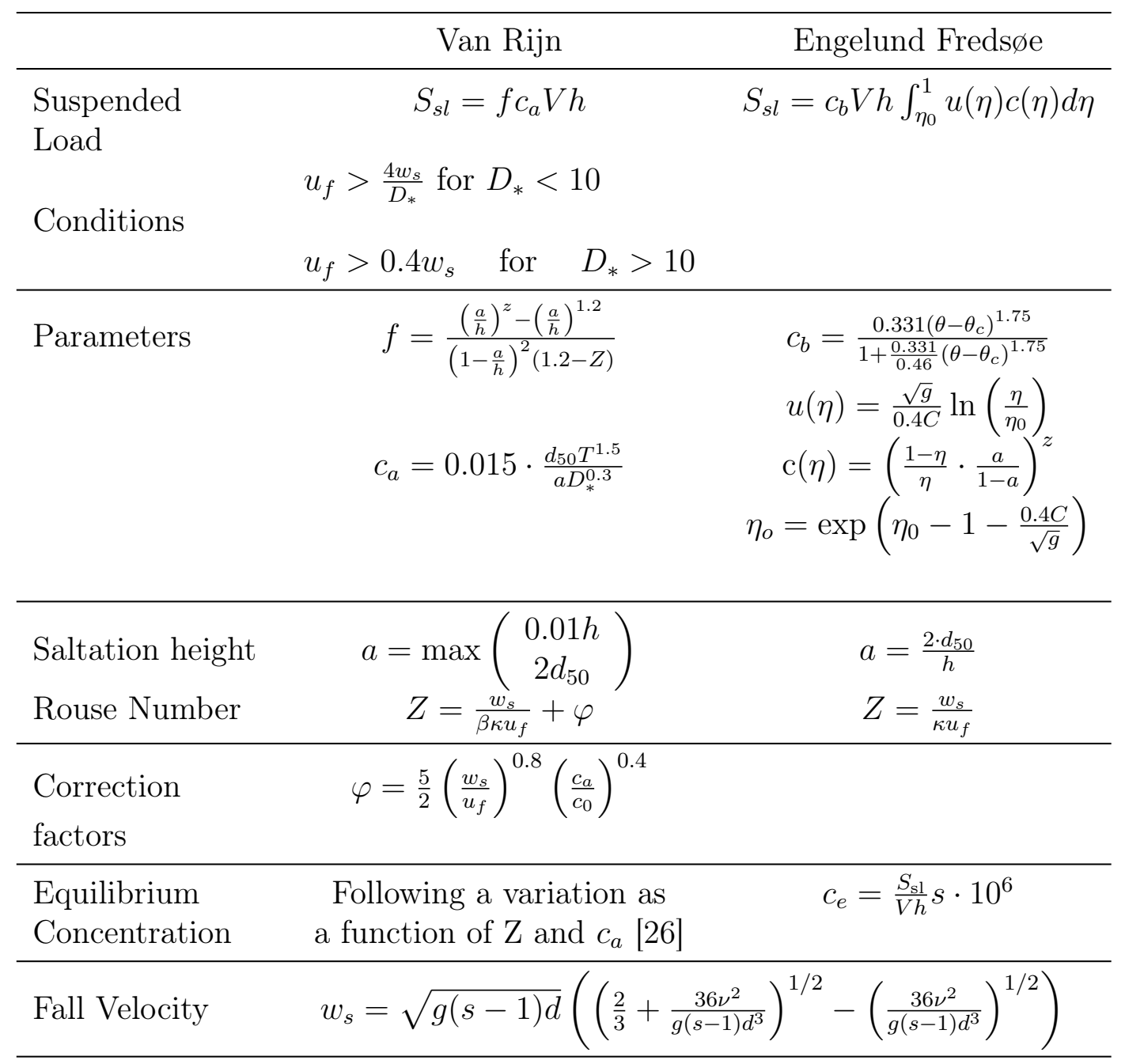




\section{References}

[1] A. E. Copping, N. K. Sather, L. Hanna, J. Whiting, G. B. Zydlewski, G. Staines, G. Gill, I. Hutchison, A. O'Hagan, T. Simas, J. Bald, C. Sparling, J. Wood, E. Madsen, Annex IV 2016 State of the Science Report: Environmental effects of marine renewable energy development around the world, Tech. rep. (2016). doi:10.1097/JNN.0b013e3182829024.

[2] S. Nash, A. Phoenix, A review of the current understanding of the hydro-environmental impacts of energy removal by tidal turbines, Renewable and Sustainable Energy Reviews 80 (2017) 648 - 662 . doi:https://doi.org/10.1016/j.rser.2017.05.289

[3] R. Martin-Short, J. Hill, S. Kramer, A. Avdis, P. Allison, M. Piggott, Tidal resource extraction in the pentland firth, uk: Potential impacts on flow regime and sediment transport in the inner sound of stroma, Renewable Energy 76 (2015) 596 - 607. doi:https://doi.org/10.1016/j.renene.2014.11. 079 .

[4] E. I. Baring-Gould, C. Christol, A. LiVecchi, S. Kramer, A. West, A Review of the Environmental Impacts for Marine and Hydrokinetic Projects to Inform Regulatory Permitting: Summary Findings from the 2015 Workshop on Marine and Hydrokinetic Technologies, Washington, D.C., Tech. rep. (2016). doi:10.2172/1263901.

[5] C. Auguste, J.-R. Nader, P. Marsh, R. Cossu, Influence of Tidal Energy Converters on sediment dynamics in tidal channel, in: Proceedings of the 13th European Wave and Tidal Energy Conference (EWTEC 2019), European wave and tidal energy conference series (EWTEC), Sustainable energy research Group, 2019.

[6] T. E. White, Status of measurement techniques for coastal sediment transport (1998).

[7] A. Sánchez, W. Wu, A Non-Equilibrium Sediment Transport Model for Coastal Inlets and Navigation Channels, Journal of Coastal Research 59 (2011) 39-48. doi:10.2112/si59-005.1.

[8] W. Wu, Z. He, Q. Lin, A. Sanchez, R. Marsooli, Non-equilibrium sediment transport modelingextensions and applications, Sediment Transport: Monitoring, Modeling and Management (2013) 179212.

[9] F. Engelund, E. Hansen, A monograph on sediment transport in alluvial streams, Tech. rep. (1967).

[10] F. Engelund, J. Fredsoe, Sediment Transport Model for Straight Alluvial Channels., Nord Hydrol 7 (1976) 293-306. doi:10.2166/nh.1976.0019.

[11] P. Ackers, W. White, Sediment transport: New approach and analysis, 1973.

[12] L. C. Van Rijn, Sediment transport,Part I: Bed load transport., Journal of Hydraulic Engineering ASCE 110 (1984) 1431-1456.

[13] L. C. Van Rijn, Sediment Transport, Part II: Suspended Load Transport, Journal of Hydraulic Engineering - ASCE 110 (1984) 1613-1641. doi:10.1061/(ASCE) 0733-9429(1984)110:11(1613).

[14] B. Camenen, P. Larroudé, Comparison of sediment transport formulae for the coastal environment, Coastal Engineering 48 (2003) 111-132. doi:10.1016/S0378-3839(03)00002-4.

[15] X. Bertin, A. Oliveira, A. B. Fortunato, Simulating morphodynamics with unstructured grids: Description and validation of a modeling system for coastal applications, Ocean Modelling 28 (2009) 75-87. doi:10.1016/j.ocemod.2008.11.001.

[16] P. A. Silva, X. Bertin, A. B. Fortunato, A. Oliveira, Intercomparison of sediment transport formulas in current and combined wave-current conditions, Journal of Coastal Research (2009) 559-563.

[17] A. B. Fortunato, X. Bertin, A. Oliveira, Space and time variability of uncertainty in morphodynamic simulations, Coastal Engineering 56 (2009) 886-894. doi:10.1016/j.coastaleng.2009.04.006

[18] A. B. Fortunato, A. Oliveira, A modeling system for tidally driven long-term morphodynamics, Journal of Hydraulic Research 42 (2004) 426-434. doi:10.1080/00221686.2004.9728408.

[19] L. Pinto, A. B. Fortunato, P. Freire, Sensitivity analysis of non-cohesive sediment transport formulae, Continental Shelf Research 26 (2006) 1826-1839. doi:10.1016/j.csr.2006.06.001.

[20] K. J. Eidsvik, Some contributions to the uncertainty of sediment transport predictions, Continental Shelf Research 24 (2004) 739-754. doi:10.1016/j.csr.2003.11.003.

[21] L. C. Van Rijn, Mathematical modeling of suspended sediment in nonuniform flows, Journal of Hydraulic Engineering 112 (1986) 433-455. doi:10.1061/(ASCE) 0733-9429(1986)112:6(433) 
[22] T. Nakato, Tests of selected sediment-transport formulas, Journal of Hydraulic Engineering 116 (1990) 362-379. doi:10.1061/(ASCE) 0733-9429(1990)116:3(362).

[23] A. Breugem, K. Delecluyse, B. Decrop, P. Luyten, COHERENS - A Coupled HydrodynamicalEcological Model for Regional and Shelf Seas: User Documentation (2014).

[24] AUSTeN, Australian tidal energy, http://austen.org.au/, 2017 Last accessed on 2019-11-30.

[25] DHI, MIKE 21 \& MIKE 3 Flow Model FM, Hydrodynamic Module Scientific documentation (2017).

[26] DHI, MIKE 21 \& MIKE 3 Flow Model FM Sand Transport Module Scientific documentation (2017).

[27] Z. Yang, T. Wang, A. E. Copping, Modeling tidal stream energy extraction and its effects on transport processes in a tidal channel and bay system using a three-dimensional coastal ocean model, Renewable Energy 50 (2013) 605 - 613. doi:https://doi.org/10.1016/j.renene.2012.07.024.

[28] S. P. Neill, J. R. Jordan, S. J. Couch, Impact of tidal energy converter (tec) arrays on the dynamics of headland sand banks, Renewable Energy 37 (2012) 387-397. doi:10.1016/j.renene.2011.07.003.

[29] P. E. Robins, S. P. Neill, M. J. Lewis, Impact of tidal-stream arrays in relation to the natural variability of sedimentary processes, Renewable Energy 72 (2014) 311-321. doi:https://doi.org/10.1016/j. renene.2014.07.037.

[30] I. Fairley, I. Masters, H. Karunarathna, The cumulative impact of tidal stream turbine arrays on sediment transport in the pentland firth, Renewable Energy 80 (2015) 755 - 769. doi:https://doi. org $/ 10.1016 / j . r e n e n e .2015 .03 .004$.

[31] A. Chatzirodou, H. Karunarathna, D. E. Reeve, 3d modelling of the impacts of in-stream horizontalaxis tidal energy converters (tecs) on offshore sandbank dynamics, Applied Ocean Research 91 (2019) 101882. doi:https://doi.org/10.1016/j.apor.2019.101882.

URL http://www.sciencedirect.com/science/article/pii/S0141118719300896

[32] J. Thiébot, D. S. Coles, A.-C. Bennis, N. Guillou, S. Neill, S. Guillou, M. Piggott, Numerical modelling of hydrodynamics and tidal energy extraction in the alderney race: a review, Philosophical Transactions of the Royal Society A: Mathematical, Physical and Engineering Sciences 378 (2178) (2020) 20190498. doi:10.1098/rsta.2019.0498.

URL https://royalsocietypublishing.org/doi/abs/10.1098/rsta.2019.0498

[33] G. Deng, Z. Zhang, Y. Li, H. Liu, W. Xu, Y. Pan, Prospective of development of large-scale tidal current turbine array: An example numerical investigation of zhejiang, china, Applied Energy 264 (2020) 114621. doi:https://doi.org/10.1016/j.apenergy.2020.114621.

URL http://www.sciencedirect.com/science/article/pii/S0306261920301331

[34] W. M. J. Batten, M. E. Harrison, A. S. Bahaj, Accuracy of the actuator disc-rans approach for predicting the performance and wake of tidal turbines, Philosophical Transactions of the Royal Society A: Mathematical, Physical and Engineering Sciences 371 (1985) (2013) 20120293. doi: $10.1098 /$ rsta.2012.0293

URL https://royalsocietypublishing.org/doi/abs/10.1098/rsta.2012.0293

[35] C. Garrett, P. Cummins, The power potential of tidal currents in channels, Proceedings of the Royal Society A: Mathematical, Physical and Engineering Sciences 461 (2005) 2563-2572. doi:10.1098/ rspa.2005.1494.

[36] S. P. Neill, E. J. Litt, S. J. Couch, A. G. Davies, The impact of tidal stream turbines on large-scale sediment dynamics, Renewable Energy 34 (12) (2009) 2803 - 2812. doi:https://doi.org/10.1016/ j.renene.2009.06.015.

[37] S. P. Neill, P. E. Robins, I. Fairley, The impact of marine renewable energy extraction on sediment dynamics, Marine Renewable Energy (2017). doi:https://doi.org/10.1007/978-3-319-53536-4_ 12 .

[38] D. Haverson, J. Bacon, H. C. Smith, V. Venugopal, Q. Xiao, Modelling the hydrodynamic and morphological impacts of a tidal stream development in ramsey sound, Renewable Energy 126 (2018) 876 -887. doi:https://doi.org/10.1016/j.renene.2018.03.084.

[39] A. N. Papanicolaou, M. Elhakeem, G. Krallis, S. Prakash, J. Edinger, Sediment transport modeling review - Current and future developments, Journal of Hydraulic Engineering 134 (2008) 1-14. doi: 10.1061/(ASCE) 0733-9429(2008) 134:1(1) 
[40] P. A. Gillibrand, R. A. Walters, J. McIlvenny, Numerical simulations of the effects of a tidal turbine array on near-bed velocity and local bed shear stress, Energies 9 (2016). doi:10.3390/en9100852.

[41] J. Fredsoe, O. H. Andersen, S. Silberg, Distribution of suspended sediment in large waves, Journal of Waterway, Port, Coastal, and Ocean Engineering 111 (1985) 1041-1059. doi:10.1061/(ASCE) 0733-950X(1985) 111:6(1041). 